\title{
Smart Device Based Localization for Ship Block Logistics
}

\author{
Kwon-Soo Song ${ }^{\dagger}$, Sangdon Lee ${ }^{++}$, Doo-Yeoun $\mathrm{Cho}^{+++}$
}

\begin{abstract}
In a ship block logistics application, acquisition of locations is required in order to identify location of the ship blocks. A Smart device equipped with a GPS sensor can be used as a mobile client for a ship block logistics application. However the precision of GPS components on a commercial smart device is not high enough. Therefore, using the GPS for localization may produce significant positioning errors in a ship block logistics system. This paper proposes a method to reduce errors in measuring locations using a smart device. Based on the knowledge of how the location information is used in a ship block logistics application, and the predictability of the client's moving line based on geographical layout of a shipyard area, our proposed technique enables a better prediction of the ship blocks location. Performance evaluation shows that the proposed technique can significantly reduce the positional error.
\end{abstract}

Key words: Shipbuilding, Ship Block Logistics, GPS, Smart Device, Localization

\section{INTRODUCTION}

A ship is built by passing through several subprocesses. The sub-processes includes steel warehousing, steel preprocessing, steel cutting, minor assembly, sub-assembly, assembly, pre-outfitting, pre-painting, pre-election, erection, etc. In each sub-process smaller parts are combined together to make a larger part. Logistics for a shipbuilding may be classified as either steel logistics, struc ${ }^{-}$ tural parts logistics or block logistics according to

※ Corresponding Author: Doo-Yeoun Cho, Address: (534-729) 61 Dorim-Ri, Chunggye-Myeon, Muan-Gun, Jeonnam, 534-729, TEL : +82-61-450-2769, FAX : +8261-452-7774, E-mail : dycho@mokpo.ac.kr

Receipt date: Oct 12, 2012, Revision date : Oct. 24, 2012 Approval date: Oct. 26, 2012

${ }^{+}$Dept. of Multimedia Engineering, Mokpo National University, Korea

(E-mail: songks68@mokpo.ac.kr)

${ }^{++}$Dept. of Multimedia Engineering, Mokpo National University, Korea

(E-mail: sdlee@mokpo.ac.kr)

${ }^{+++}$Dept. of Naval Architecture \& Marine Engineering, Mokpo National University, Korea

※ This work was supported by the Industrial Strategic Technology Development Program(10035331, Simulationbased Manufacturing Technology for Ships and Offshore Plants) funded by the Ministry of Knowledge Economy (MKE, Korea). the unit of the handled parts, as described in the Fig. 1. The main purpose of the logistics system is to reduce the production cost of shipbuilding by managing space and time spent during the production process as efficiently as possible[1,2].

In order to reduce the shipbuilding cost, it is very important to keep to the production schedule for the building of all the parts and blocks of a ship[3]. As the resources -including the space for assembly shop - are limited in a shipyard, they need to be exploited in a very efficient way. While being assembled, each ship block is moved from one block assembly shop to another. A ship block logistics system monitors and keeps track of the building status of each block [1]. For this, locating a ship block is essential in the ship block logistics.

There are numerous ways to locate and collect location information of ship blocks, ranging from manual approaches to fully automated ones [4-6]. Each alternative requires a different setting of the workplace and devices used for it. This will also affect the cost necessary for employing the applied approach.

We are on the progress of building a ship block logistics system that supports the monitoring of ship blocks by using mobile devices [1]. In this pa- 


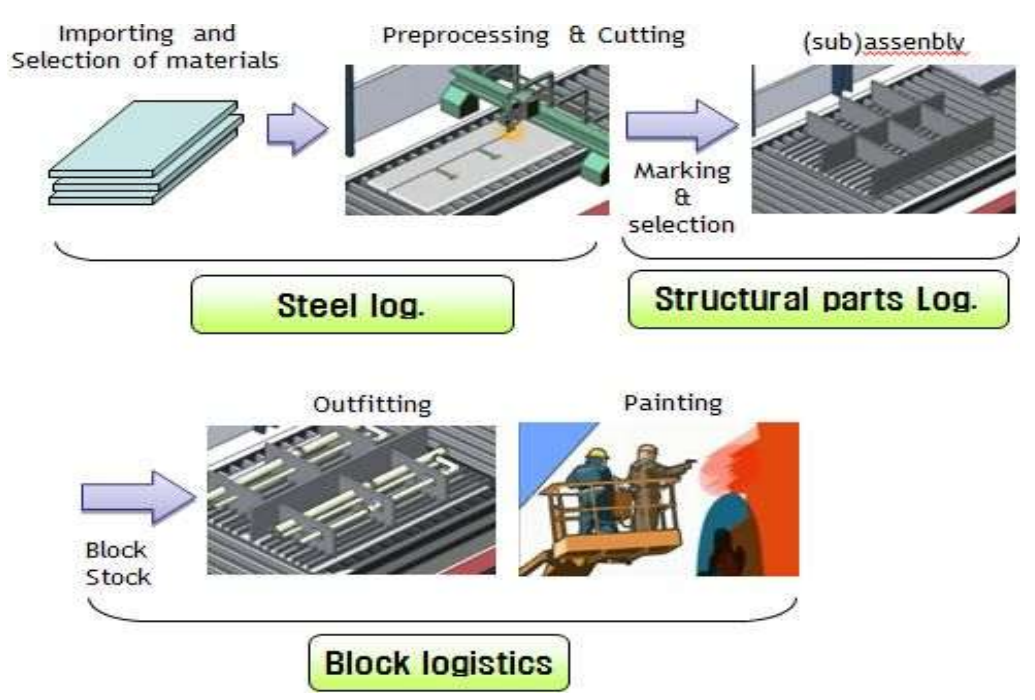

Fig. 1. A shipbuilding process.

per we try to tackle some of questions raised during the system building process.

- How can mobile devices like smart pads be used as the main tools to efficiently capture information for the logistics system?

- How can standardized and commercialized smart devices be involved for economically localizing ship blocks?

The rest of the paper is organized as follows. Section 2 briefly describes the overall concept of the mobile ship block logistics system, and introduces the role of smart devices as the main tools for mobile localization of ship blocks. Section $3 \mathrm{de}^{-}$ scribes preliminary experiments to see the possibility of using smart devices for localization of ship blocks. From these experiments we identify the problems and the possible suggestions to mitigate the negative influence of the identified problems. Section 4 proposes our suggestion to reduce the errors of smart devices for estimating the location of ship blocks. Section 5 explains the results of $\mathrm{ex}^{-}$ periments by using our proposed approach. Finally section 6 concludes this paper.

\section{A MOBILE SHIP BLOCK LOGISTICS SYSTEM}

A mobile ship block logistics system is com- posed of the logistics server that manages all the information regarding the ship block logistics and mobile clients that are built on mobile devices such as smart pads. The mobile client displays current logistics data on a smart device and acquires data that can be obtained from the shipyard, such as the current processing status of some ship blocks. Some of the typical questions that may be asked regarding the ship block logistics system are as follows.

- Where is the ship block $\mathrm{X}$ and what is the building status of it?

- Which ship blocks are in Y ship block assembly shop, and what are their statuses?

- Ship block Z in a ship block assembly shop $\mathrm{Y}$ has been finished. Where should it be moved for the next processing step?

- Which are the ship blocks that are scheduled to be completed today, and how can each one of them be located?

The location of a ship block is one of the important data that needs to be handled in a mobile ship block logistics system. Acquisition of the location information can be achieved in diverse ways; A worker may identify the predetermined geographical address of the area that contains the target ship block in a shipyard, or a GPS sensor can be employed to get location data for a ship 
block [3].

When using GPS, the accuracy of the location data may be affected considerably based on which type of GPS components are used. High precision location data with errors less than $1 \mathrm{~m}$ can be obtained when elaborate and expensive GPS components are used. On the contrary, using a cheaper GPS component will increase the range of errors in location estimation. Therefore, acquiring location data in a ship block logistics also requires a compromise between the precision of the acquired location data and cost of the GPS components.

Smart devices including smart phones and smart pads can also be used for ship block localization by installing a mobile client application on them. One thing that must be considered for using commercialized smart devices for ship block localization is that they are equipped with GPS components that have relatively low precision.

Fig. 2 shows a ship block localization system using smart devices with GPS components [2]. A smart device is used to identify the current geographic location, with an auxiliary hand-held GPS facility attached, if necessary. The smart device record the location of each ship block while it moves along a block assembly shop. Later, it is also used to identify ship blocks positioned nearby.

Although using the smart devices as tools for ship block localization allows economic building of the mobile ship block logistics system, the smart devices may produce location data with positioning errors up to 10-30 meters [4], which may cause imprecise tracking of ship blocks in a ship block logistics system. This wide error range for location estimation may greatly reduce the utility of smart devices as client devices for the mobile ship block logistics system. So it is essential to find a solution to reduce the range of positional errors of smart devices.

\section{ACQUIRING LOCATION USING A SMART DEVICE}

In this section we explore applicability of smart devices to get location information for ship blocks. For this we performed experiments to obtain location data of some already known ship block assembly shops at a real shipyard using commercialized smart devices. Although the test environment and the test devices as well as the type of the GPS sensors on the test devices were very restricted, we believe that the results from the experiments reveal the inherent characteristics of the phenomena that can be observed from typical ship block logistics environments.

We also explore the characteristics of the processes and the environments of location identification in the ship block logistics. This will help

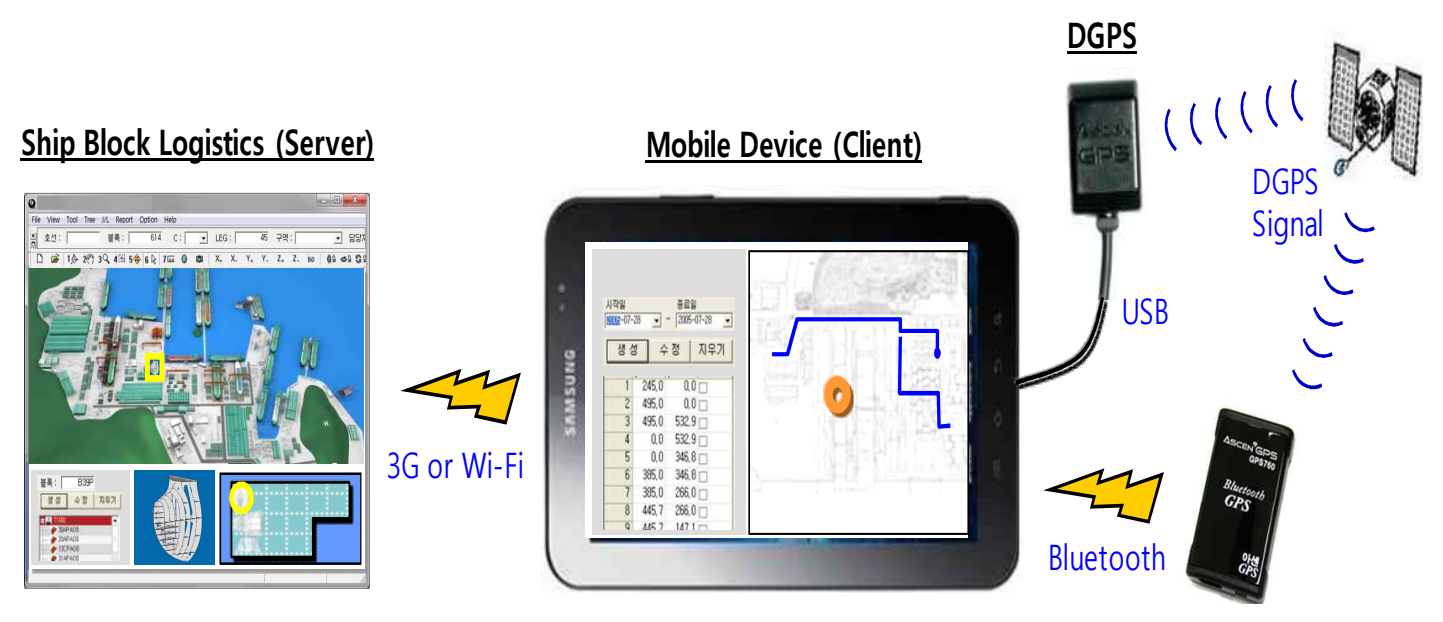

Fig. 2. A ship block logistics system 
identify any possible solution to mitigate the impacts of the low precision GPS components of smart devices.

\subsection{Experimental Setup}

The procedure for the experiments is as follows:

1. We selected two sample test places with different conditions.

2. Regular shape test tracks were selected.

3. Two smart phones were used to get location data while a tester walked along the $\mathrm{de}^{-}$ termined track. The smart phones were set up to use two different GPS devices. At observing points the tester paused for a while to get stable location data from the smart phones.

4. The shape of the acquired location data was compared with that of the traversed track that the tester followed.

The regularity of the shape makes it easier to identify the difference between the location data of the measured points and those of an actual test place.

For the experiments two different test places were selected in order to check the impacts from the different test environments:

- Around a university soccer field

- Around a ship block subassembly shop in a shipyard

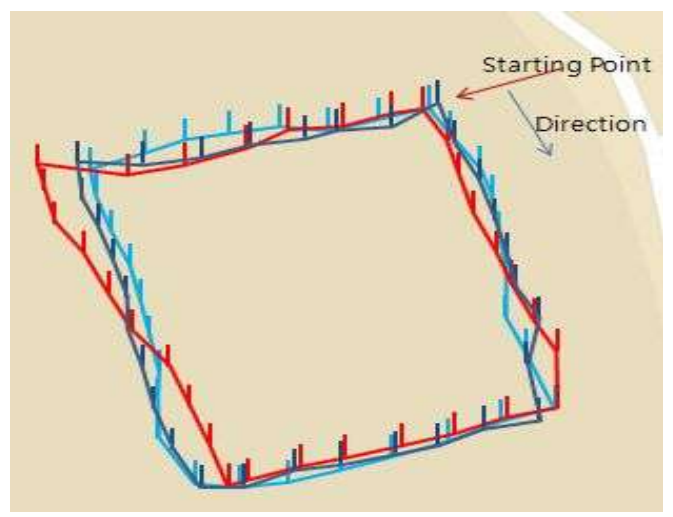

a) Using an embedded GPS component
We also used two different types of GPS components:

- A GPS component embedded in the smart device.

- An external DGPS device with the Bluetooth channel that can be attached to a smart phone, which can be used to transfer location data measured by the device.

\subsection{Preliminary Results}

Fig. 3 shows the results of location acquisition along a soccer field in a university. The results show that the recording of the measured location were done three times by traversing the contour of the soccer field. Considering that the shape of the soccer field is rectangular, visual comparison of the shape of the figures formed by connecting the measured points from the experiments shows how the measured results deviates from the real track. We can also see the relative accuracy of the measured results from the two GPS components by comparing the two resultant shapes. It shows that the external DGPS component(part $b$ of the figure) shows better accuracy in this case.

In the second test environment, we selected a ship block assembly shop where actual ship blocks are being assembled. Around the block assembly shop lie a lot of iron structural parts used for the assembly process. Also the shop itself is a big iron

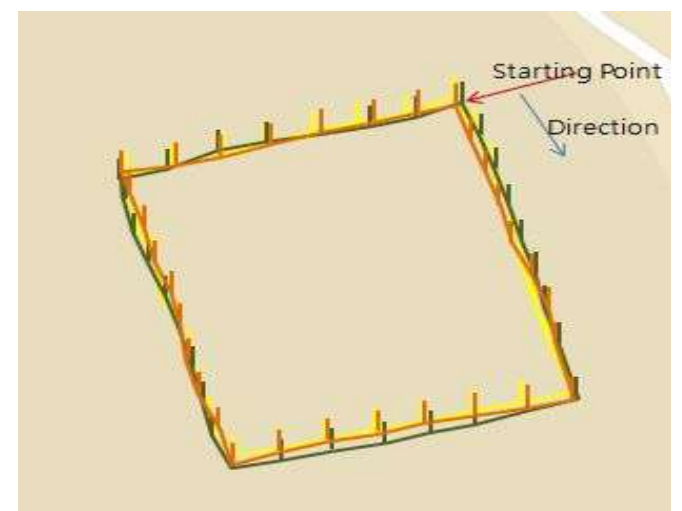

b) Using an external DGPS component

Fig. 3. A ship block logistics system 
structure as shown in the picture of the Fig. 4. For the experiment a simple track in a rectangular shape has been set up in along the assembly shop.

Fig. 5 shows the result of measuring location at the test ship block assembly shop. Compared to the soccer field case, there exists a lot more distortion in the shape of the measured results. The results in the figure 5 indicate that the case using DGPS shows more distortion. But some other tests conducted at different areas in a shipyard have shown conflicting results. Although it was not clear from the tests at the ship block assembly shop which of the two GPS component was superior to the other, the general tendency was that the location measurement at the shipyard environment was never accurate than the soccer field case. We believe that the shipyard environment negatively af-

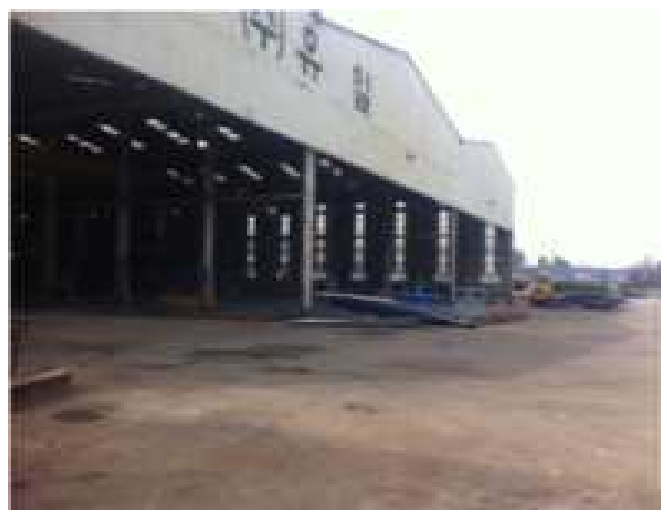

a) The test place fects the accuracy of the GPS components for location measurement.

\subsection{Lessons}

Our results from the preliminary experiments show that measuring location using GPS components on smartp hones may incur considerable errors. It may experience even higher errors in a real shipyard environment. This implies that using smart devices for localization in a shipyard might need some other means to cope with increasing GPS positional errors. In the following section, we propose a method to improve positional errors of the GPS components in smart phones based on the typical access pattern of location-related data in a ship block logistics application for a shipyard.

Fig. 4. The test ship block assembly shop

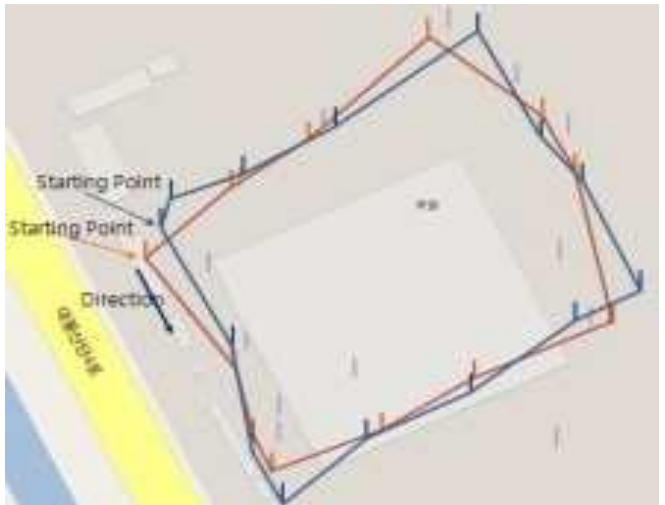

a) Using an embedded GPS component

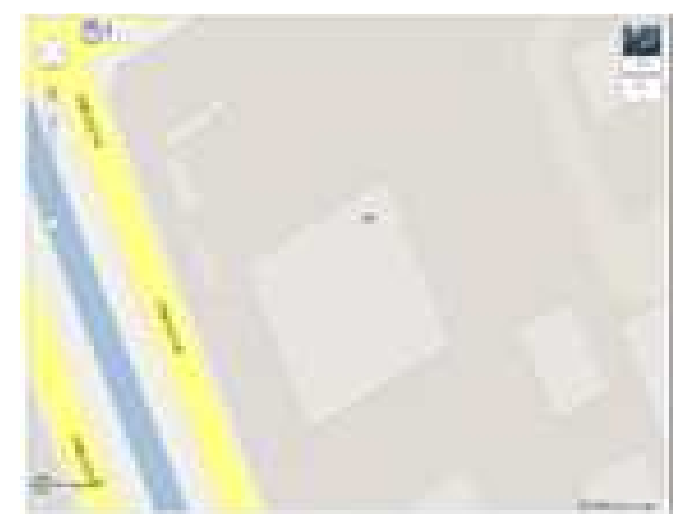

b) The test place in the Google map

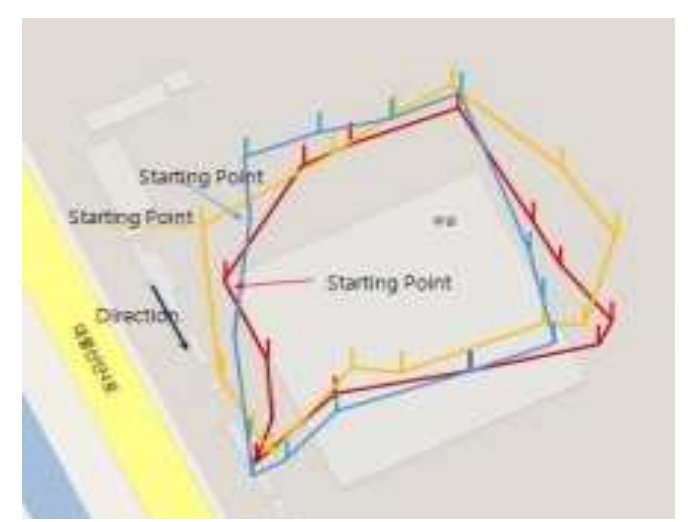

b) Using an external DGPS component

Fig. 5. Measuring location at a shipyard 


\section{APPROXIMATION OF LOCATION USING SHIPYARD-SPECIFIC KNOW- LEDGE}

\subsection{Usage pattern of location data in a ship block logistics application}

In a ship block logistics application, locating a block or a stock area for the ship block in a shipyard is essential to monitor the work process of each ship block. For an example, the procedure to move a ship block B, from a place in a yard to another is as follows:

- Locate the current assembly shop (say S1) where $\mathrm{B}$ is.

- Locate the assembly shop (say S2) where B will be moved.

- Move a transporter to the assembly shop S1

- Load B on to the transporter, move to R2, and unload B onto S2.

- The location of B is changed from S1 to S2 in the ship block logistics system.

A smart device can be used as a mobile client to identify the location for a ship block, or a stock area. In order to perform the work described above, the transporter usually moves along the $\mathrm{de}^{-}$ termined path in a shipyard. In other words, a smart device, which is used to measure the location, moves along the predetermined path. This implies that as a user with the mobile client starts to move, the path to follow is determined. There have been some researches that consider a series of location as a path, or a trajectory, and construct a trajectory model $[7,8]$ based on that. The model can be used for various location-based services [9,10]. An approach of estimating position of a moving object using a GPS and an accelerometer has also been suggested[11].

In the Fig. 6 , in order to move a ship block from the stock area S1 to S2, a worker with the smart device will follow the path designated by the dashed line. This implies that the location measured by a smart device while the block is moving

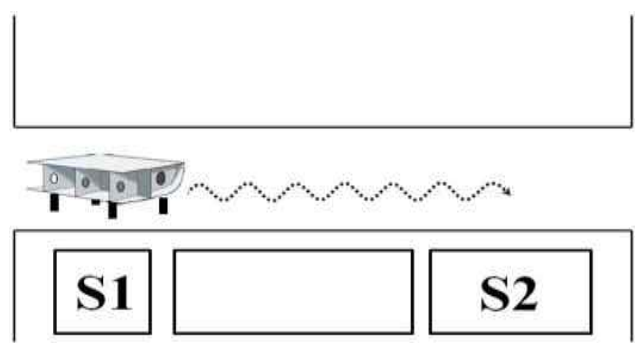

Fig. 6. Moving a ship block from S1 to S2

will be almost on the straight line formed by the path from S1 to S2.

This predictable way of using paths in a ship block logistics application can be very helpful to estimate(or proximate) the location measured by a smart device with less errors.

\subsection{Approximating the location}

Based on the observation described in the previous section, we propose a method that estimates a revised position from the location information gathered by a smart device. For our method, we assume the followings:

- A smart device is used to acquire current position when the location information is necessary. A worker, or a transporter, may carry the smart device.

- There are some pre-identified places in a shipyard, which we call "base points." The base points can be observed at a shipyard, and can be marked at the right positions on a map of the shipyard.

- A client, or more precisely, a worker who carries the mobile client, knows its moving direction. He also knows the two base points at the shipyard and the path he is taking. The two base points are at either end of the path.

Next, the procedure to get the revised position is as follows:

1. If a position currently being measured, $P_{c}$, corresponds to one of the base points, map the current position to the corresponding base point. 


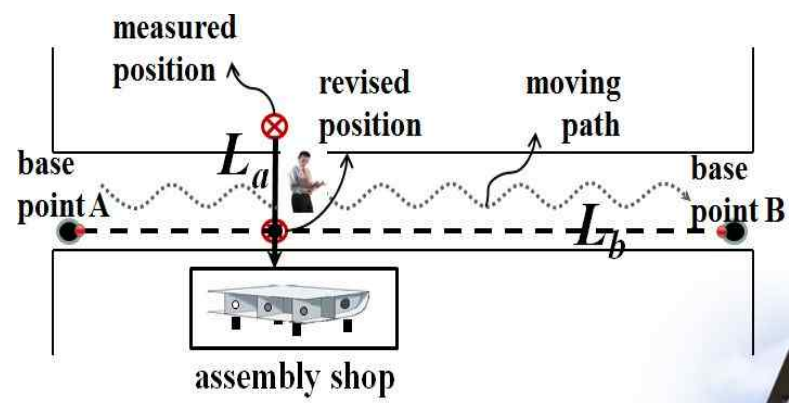

Fig. 7. Approximating revised positions

2. Otherwise identify the two base points that lies at either end of the path that is taken.

3. The straight line formed by connecting the two base points is designated as $L_{b}$.

4. Draw a line, $L_{a}$, which passes through $P_{c}$, and is perpendicular to $L_{b}$.

5. Set the revised position, $\mathrm{P}_{\mathrm{r}}$, to the crossing point of $L_{a}$ and $L_{b}$.

Fig. 7 demonstrates how to obtain the revised position as a worker walks along a path from the base point $\mathrm{A}$ to the other base point $\mathrm{B}$.

Fig. 8 demonstrates an example of determining revised positions by applying the proposed method. Fig. 8a shows the original measures with significant positional errors Fig. 8b shows 4 base points that each correspond to the corners of a ship block assembly shop. Fig. 8c shows how to map the observed location to the revised one by applying our method. Arrows with dashed line show the determination of the revised position for each measured position.

\section{EVALUATION}

\subsection{Setup for experiments}

In order to evaluate the validity of the proposed method, we devised the experiment as follows:

- Select a ship block in a real shipyard.

- Draw a rectangle around the ship block, whose size is slightly bigger than the ship block. This will be used as the track the smart device follows.

- Set 4 corners of the rectangle as the 4 base points.

- While walking along the rectangle, measure the location at every unit distance.

The size of the target ship block was $22 \times 26$ meters with 2 meters high. The block lies on the 2 -meters-high jig. The size of the rectangle was set to $24 \times 28$ meters. The location was recorded using a smart phone, while keeping the phone 1 meter high from the ground. The unit distance was set to 1 meter, which means that starting from a base point we will measure the location every 1 meter using the smart phone.

\subsection{Performance metric}

In measuring the effect of reducing positional error between two locations by the proposed technique, we use the performance metric of the difference of the distance errors (denoted as $D D R$ ).

The distance error (DR) and the $D D R$ is $\mathrm{de}^{-}$ fined as follows.

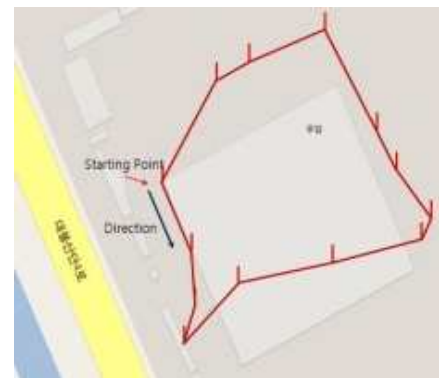

a) Pre-Correction

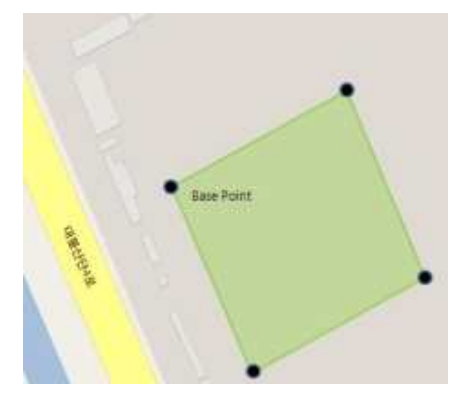

b) Base points

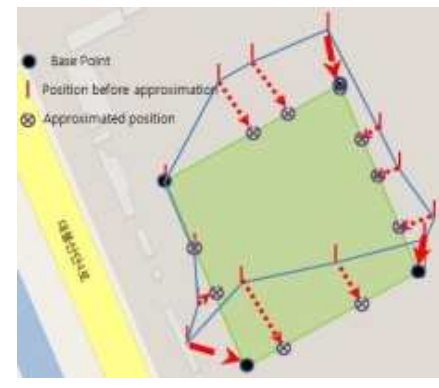

c) Revised positions

Fig. 8. An example of location approximation. 


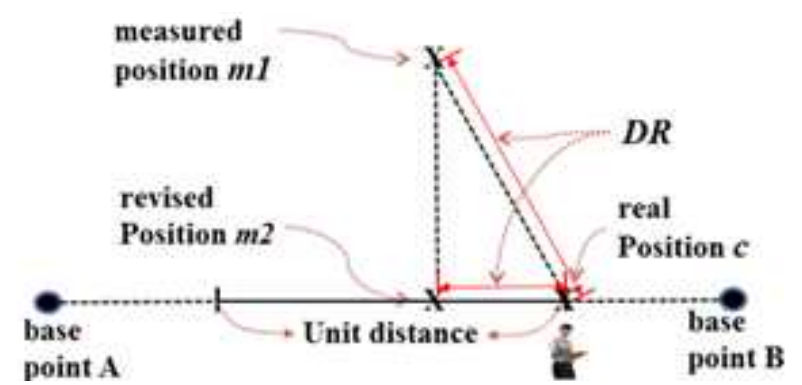

Fig. 9. Concept of the distance error.

Assume that there are two locations, $m$ and $c$, where $c$ indicates the known, accurate(or correct) location, and $m$ indicates the measured location at the location $c$. Note that although $m$ was measured at the location $c, m$ may not coincide with $c$ because of errors in the measuring device or from other reason. Then the distance error between $m$ and $c, D R(m, c)$, is defined to be the Euclidian distance from $c$ to $m$.

Based on the definition of the distance error, the difference of the distance error $(D D R)$ can be defined as the difference of two distance errors, one of which is between $m 1$ and $c$, the other between $m 2$ and $c$. Note that the two distance errors in the $D D R$ contain the same correct location $c$.

Fig. 9 explains the details of the concept of the distance error. Assume that we know the locations for the two base points, $A$ and $B$. If we follow the line formed by the two base points by the unit distance, we can know the current correct location $c$. At $\mathrm{c}$ we can get the measured location, $m 1$, by measuring its location using a smart device. We can also get the revised position, $m 2$, by applying the proposed technique described in the section 4 . Now we can get the $D R(m 1, c)$ and $D R(m 2, c)$. Then the $D D R(m 1, m 2)$ is calculated by $D R(m 1$, c) $-D R(m 2, c)$

The $D D R(\mathrm{ml}, \mathrm{m} 2)$ is interpreted to be the $\mathrm{de}^{-}$ gree of improvements of the positional error by approximating $m 1$ to $m 2$. The bigger $D D R$ ( $m 1, m 2$ ), the more the proposed technique improves the positional errors. The improvement ratio can be $\mathrm{de}^{-}$ rived as to $D D R(m 1, m 2) / D R(m 1, c)$.

\subsection{Results}

The experiments have been repeated 3 rounds for the GPS components embedded in the smart device, and an external DGPS component, respectively. Fig. 10 shows the first round test for the external DGPS component connected with the test smart phone. The ID for the measured location starts from 1 to 105 in the $1^{\text {st }}$ round test. The ID

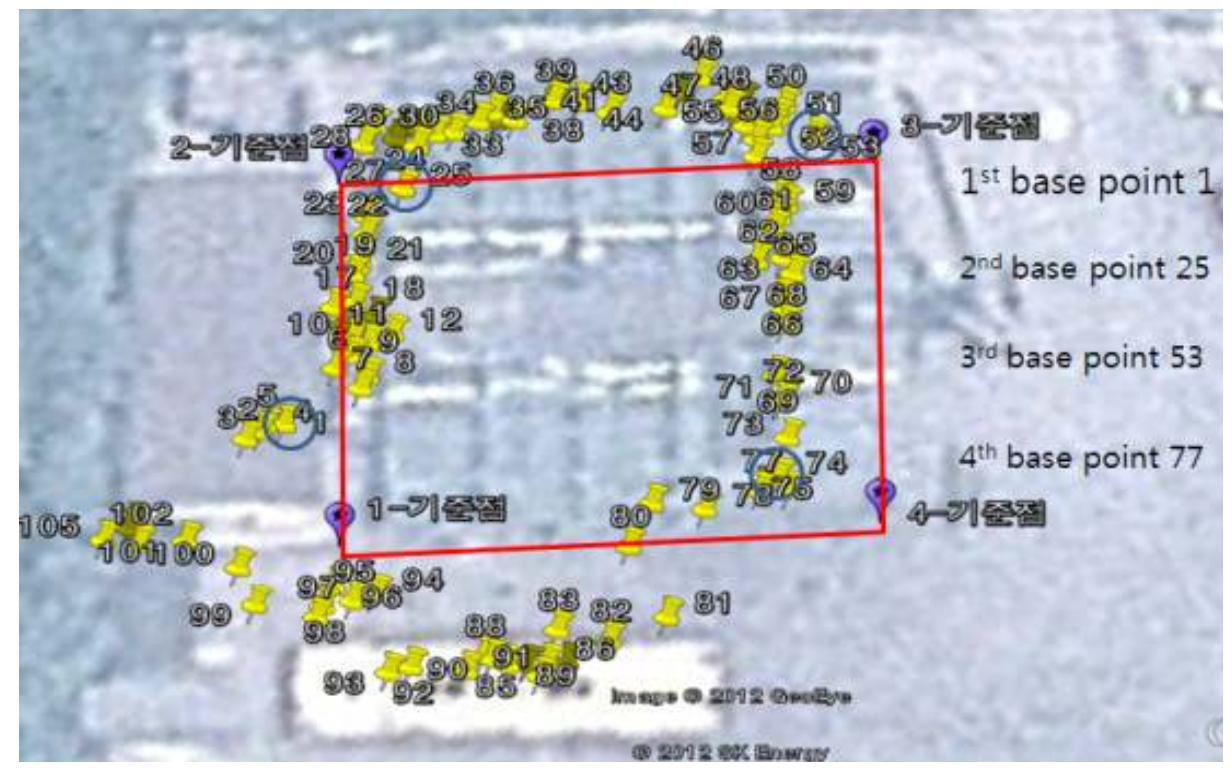

Fig. 10 The $1^{\text {st }}$ round for the DGPS component. 


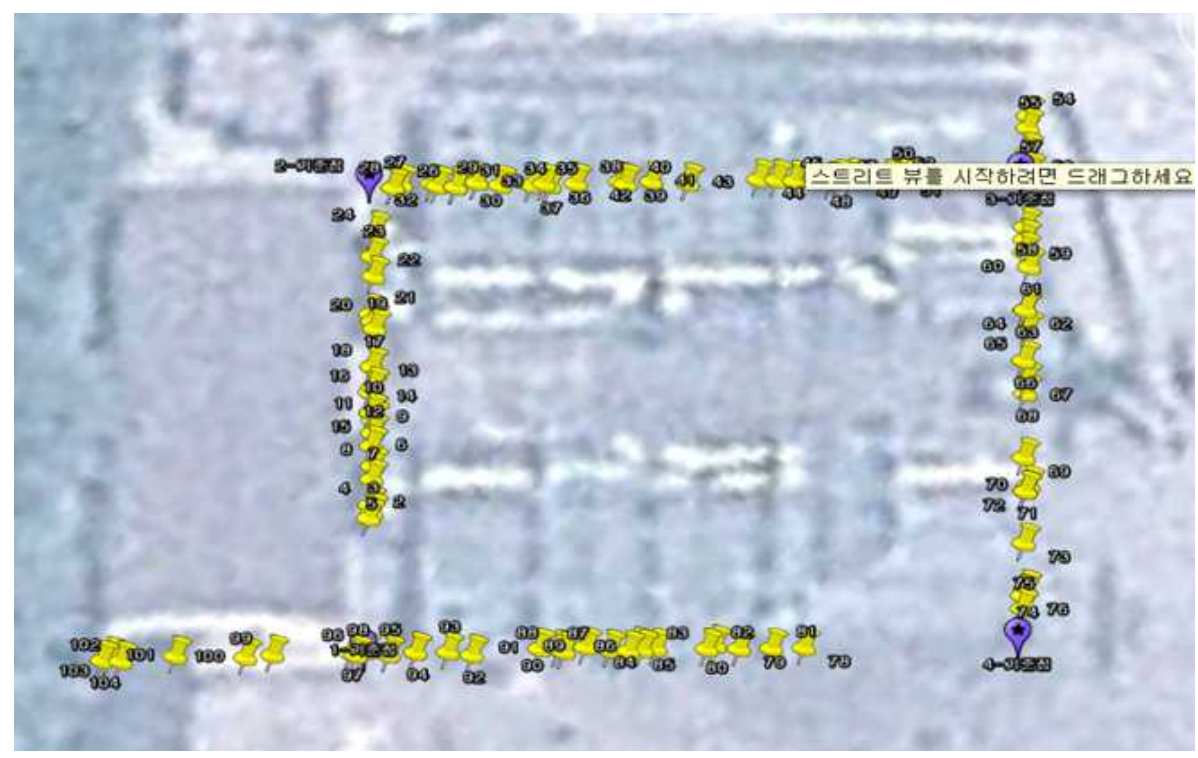

Fig. 11. The approximated result for the $1^{\text {st }}$ round data for the DGPS component

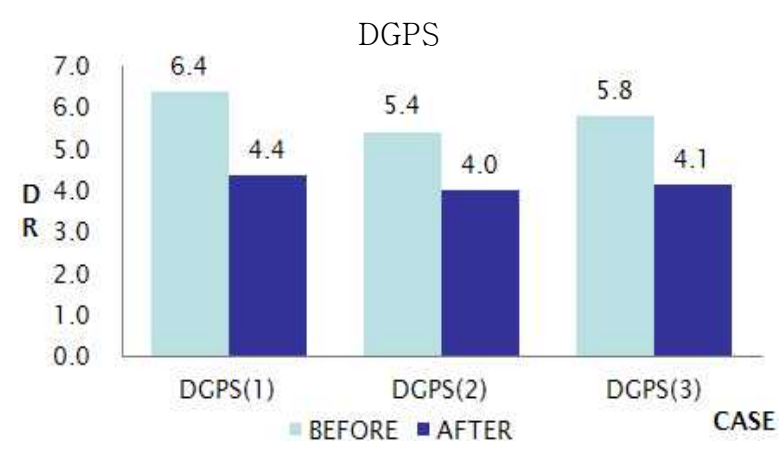

Fig. 12. The DRs before and after (DGPS).

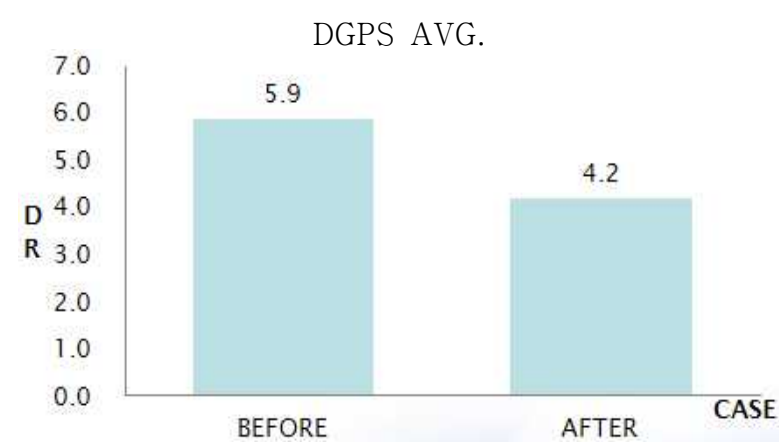

Fig. 13. The average of DRs before and after (DGPS).

of the measured location for each base point is 1 , 25, 53 and 77 .

Fig. 11 shows the result locations that are approximated by our technique.

Fig. 12 represents the distance errors before and after the approximation for each 3 round of the
Table 1. Summary of the results for the DGPS case

\begin{tabular}{|c|c|c|c|}
\hline & BEFORE & AFTER & RATIO \\
\hline \hline DGPS(1) & 6.4 & 4.4 & 31.8 \\
\hline DGPS(2) & 5.4 & 4.0 & 26.4 \\
\hline DGPS(3) & 5.8 & 4.1 & 28.6 \\
\hline DGPS(Avg.) & 5.9 & 4.2 & 29.1 \\
\hline
\end{tabular}

DGPS cases. It shows that after applying our technique the DRs are reduced consistently and considerably. Fig. 13 shows the average DRs of the DGPS case. As summarized in the Table 1, the average improvement ratio of DR records 29\%.

Fig. 14 represents the distance errors before and after the approximation for each 3 round of the GPS cases. It also shows that the DRs after applying

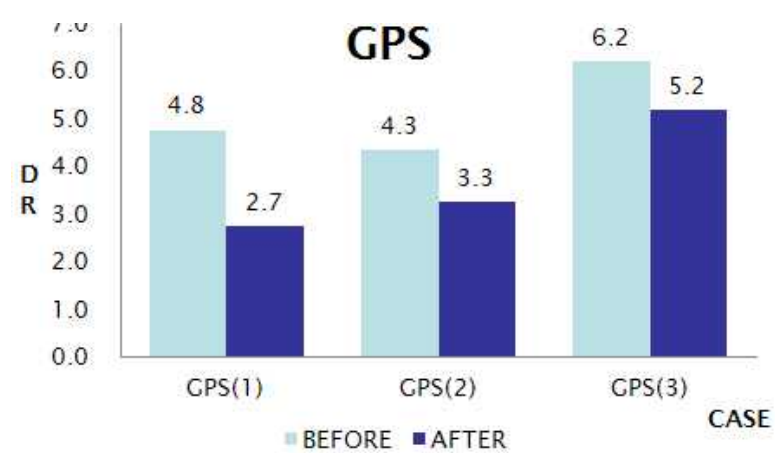

Fig. 14. The DRs before and after (GPS). 


\section{GPS AVG.}

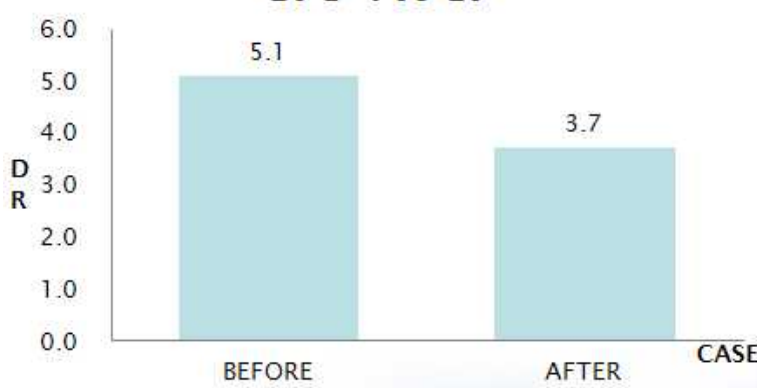

Fig. 15. The average of DRs before and after (GPS).

Table 2. Summary of the results for the GPS

\begin{tabular}{|c|c|c|c|}
\hline & BEFORE & AFTER & RATIO \\
\hline \hline GPS(1) & 4.8 & 2.7 & 42.6 \\
\hline GPS(2) & 4.3 & 3.3 & 24.9 \\
\hline GPS(3) & 6.2 & 5.2 & 16.5 \\
\hline GPS(Avg.) & 5.1 & 3.7 & 27.0 \\
\hline
\end{tabular}

our technique are reduced consistently and considerably. Fig. 15 shows the average DRs of the DGPS case. As summarized in the Table 2, the average improvement ratio of DR is $27 \%$.

To summarize the results of experiments, our proposed technique can reduce the errors in measuring location using GPS (or other types of components like DGPS) component significantly.

\section{CONCLUSIONS}

Because smart devices are portable and easy to handle, they are useful as mobile clients of a ship block logistics system. In a ship block logistics application, acquisition of locations is required to identify the location of ship blocks. Smart devices equipped with GPS components, or an external GPS component may be connected to them. However the precision of the GPS components on commercial smart devices are not high enough. As we demonstrated in the preliminary experiments, they tend to be more prone to error in a real shipyard environment.

In order to find a solution to use smart device as a mobile clients for a ship block logistics appli- cation, we propose a method to reduce errors in measuring location using them. For this we have described preliminary explorations on the applicability of some smart devices for localization in a ship block logistics application. Based on the knowledge of how the location information is used in a ship block logistics application, and the predictability of the client's moving line based on geographical layout of a shipyard area, this paper has proposed a technique to reduce positioning errors from GPS components of smart devices by approximating possibly erroneous position to a revised one.

We have showed the validity of our approach by measuring the accuracy of approximation through successive experiments. They have showed that the accuracy has been improved up to around $30 \%$ in average.

This paper has focused on the case that the path is linear. Although a curve can be approximated by a series of lines, further works include an $\mathrm{ex}^{-}$ tension of the proposed method for more complex and nonlinear path.

\section{REFERENCES}

[1] Mi-Sun Kim, Kwon-Soo Song, Sangdon Lee, and Doo-Yeoun Cho, "Design of A Ship Block Management System Based on The Android Mobile Platform," Proc. of KISM Spring Conference 2012, Vol. 1, No. 1, pp. 121-129, 2012.

[2] Kwon-Soo Song, Mi-Sun Kim, Sangdon Lee, and Doo-Yeoun Cho, "A GPS Based Ship Block Location System for The Ship Block Logistics," Proc. of The Korea Multimedia Society Spring Conference 2012, Vol. 15 No. 1, pp. 168, 2012.

[3] Kyong-Ho Han, et al., " $A$ Study on Enhancing Precision for Mid and Small size Ship Block Assembly, "Final Report of Regional Industry Promotion \& Development Research, Ministry 
of Commerce, Industry and Energy, Seoul, 2006.

[4] A. Farrell and Matthew Barth, "The Global Positioning System \& Inertial Navigation," Mchraw-Hill, N.Y., 1999.

[5] Data Download Service, http://gps.ngii.go.kr, 2012.

[6] J. Hightower and G. Borriello, A Survey and Taxonomy of Location Systems for Ubiquitous Computing, Technical Report UWCSE-01-08-03, University of Washington, 2001.

[7] Yu Zheng, Quannan Li, Yukun Chen, Xing Xie, and Wei-Ying $\mathrm{Ma}$, "Understanding Mobility Based on GPS Data," Proc. of ACM conference on Ubiquitous Computing (UbiComp 2008), pp. 312- 321, 2008.

[8] Daniel Ashbrook and Thad Starner, "Using GPS to Learn Significant Locations and Predict Movement Across Multiple Users," Proc. of the 6th IEEE Inter, Symposium on Wearable Computers, Vol. 7, No. 5, pp. 275-286, 2003.

[9] Zaiben Chen, Heng Tao Shen, Xiaofang Zhou, $\mathrm{Yu}$ Zheng, and Xing Xie, "Searching Trajectories by Locations - An Efficiency Study," Proc. of the 2010 International Conference on Management of Data, pp. 255-266, 2010.

[10] Xiong Liu and Hassan A. Karimi, "Location Awareness Through Trajectory Prediction," Computer, Environment and Urban Systems, Vol. 30, No. 6, pp. 741-756, 2006.

[11] Jeong-Nam Yeom, Geum-Boon Lee, JeongJin Park, and Beom-Joon Cho, "Position Estimation System of Moving Object using GPS and Accelerometer," Journal of Korea Multimedia Society, Vol. 12, No., 4, pp. 600607, 2009.

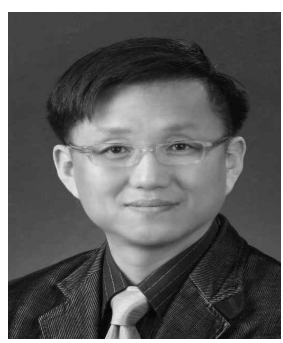

\section{Kwon-Soo Song}

He received the B.S., M.S., in computer science and statistics, M.A degrees in computer science from Mokpo National University, Korea in 1993, 1995, and 2000 respectively. He has been a graduate student(Ph.D. degree) in department of multimedia engineering, Mokpo National University since 2007. His main research interests include multimedia contents, multimedia software and positioning system.

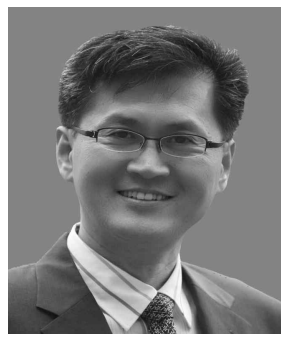

\section{Sangdon Lee}

He received the B.S., M.S., and Ph.D. degrees in computer engineering from Seoul National University, Korea in 1984, 1986 and 1996 respectively. He worked for Research and Development Group, Korea Telecom from 1987 to 1997 . In 1997 he joined the department of multimedia engineering, Mokpo National University, Korea. He served as a visiting professor in computer science, Brown University, USA from 2001 to 2002. His main research interests include multimedia information management, ubiquitous information processing and applications.

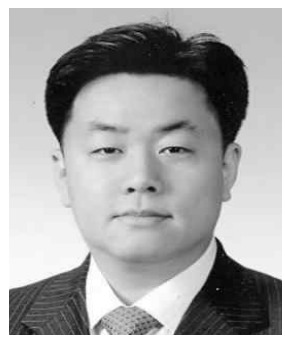

\section{Doo-Yeoun Cho}

He received the B.S., M.S., and Ph.D. degrees in naval architecture and ocean engineering from Seoul National University, Korea in 1997, 1999 and 2005 respectively. In 2007 he joined the department of naval architecture and marine engineering, Mokpo National University, Korea. His main research interests include $\mathrm{CAD} / \mathrm{CAM}$ for shipbuilding, design automation and simulation for manufacturing and logistics. 